Article

\title{
Variation Characteristics and Influencing Factors of Soil Moisture Content in the Lime Concretion Black Soil Region in Northern Anhui
}

\author{
Mingcheng Du 1,2,3, Jianyun Zhang 1,2,3, Amgad Elmahdi ${ }^{4}\left(\mathbb{D}\right.$, Zhenlong Wang ${ }^{5,6}$, Qinli Yang ${ }^{7}$, Haowen Liu ${ }^{2,3,8}$, \\ Cuishan Liu ${ }^{2,3}$, Yongsheng $\mathrm{Hu}^{5,6}$, Nan Gu ${ }^{2,3} \mathbb{D}$, Zhenxin Bao ${ }^{2,3} \mathbb{D}$, Yanli Liu ${ }^{2,3} \mathbb{D}$, Junliang Jin ${ }^{2,3}$ \\ and Guoqing Wang 2,3,*(D)
}

check for updates

Citation: Du, M.; Zhang, J.; Elmahdi, A.; Wang, Z.; Yang, Q.; Liu, H.; Liu,

C.; Hu, Y.; Gu, N.; Bao, Z.; et al.

Variation Characteristics and

Influencing Factors of Soil Moisture Content in the Lime Concretion Black Soil Region in Northern Anhui. Water 2021, 13, 2251. https://doi.org/ $10.3390 / w 13162251$

Academic Editor: Athanasios Loukas

Received: 13 July 2021

Accepted: 16 August 2021

Published: 18 August 2021

Publisher's Note: MDPI stays neutral with regard to jurisdictional claims in published maps and institutional affiliations.

Copyright: (c) 2021 by the authors. Licensee MDPI, Basel, Switzerland. This article is an open access article distributed under the terms and conditions of the Creative Commons Attribution (CC BY) license (https:// creativecommons.org/licenses/by/ $4.0 /)$.
1 School of Civil Engineering, Tianjin University, Tianjin 300350, China; mingchengd@163.com (M.D.); jyzhang@nhri.cn (J.Z.)

2 State Key Laboratory of Hydrology-Water Resources and Hydraulic Engineering, Nanjing Hydraulic Research Institute, Nanjing 210029, China; 2019323060016@stu.scu.edu.cn (H.L.); csliu@nhri.cn (C.L.); nanguskrskr@163.com (N.G.); zxbao@nhri.cn (Z.B.); ylliu@nhri.cn (Y.L.); jljin@nhri.cn (J.J.)

3 Yangtze Institute for Conservation and Development, Nanjing 210098, China

4 MENA Region-International Water Management Institute-IWMI, Cairo 3000, Egypt; A.Elmahdi@cgiar.org

5 Wudaogou Experimental Station for Hydrology and Water Resources, Bengbu 233704, China; skywzl@sina.com (Z.W.); h18096521976@163.com (Y.H.)

6 Anhui Province Key Laboratory of Water Conservancy and Water Resources, Anhui and Huaihe River Institute of Hydraulic Research, Bengbu 233000, China

7 School of Resources and Environment, University of Electronic Science and Technology of China, Chengdu 611731, China; qinli.yang@uestc.edu.cn

8 College of Water Resource \& Hydropower, Sichuan University, Chengdu 610065, China

* Correspondence: gqwang@nhri.cn

\begin{abstract}
Soil moisture content (SMC) is an important factor affecting crop growth. Based on the field SMC data measured at the Wudaogou experimental station from 1989 to 2019, two typical crop types, wheat and maize, were selected. By combining the groundwater depth, crop growth period, and meteorological factors in the same period, and using classical statistics and redundant analysis (RDA) methods, the characteristics and influencing factors of SMC changes in vertical profiles of different crops were compared and analyzed. The results showed that the SMC and average daily water storage of wheat were greater than that of maize. The crop growth mainly consumed 0-60 cm $\mathrm{SMC}$. The SMC in this area was moderately variable; the SMC of $0-30 \mathrm{~cm}$ belongs to the active layer, and the SMC of 30-100 cm belongs to the sub-active layer. The RDA method identified ground temperature, groundwater depth, relative humidity, and the wheat growing period as the main factors affecting soil moisture variation in wheat fields; groundwater depth, relative humidity, and water vapor pressure differences were the main factors affecting soil moisture variation in maize fields. The results can provide a basis for accurate prediction of soil water dynamics and thus provide a reference for irrigation decision-makers.
\end{abstract}

Keywords: wheat; maize; soil moisture content; lime concretion black soil; meteorological factor; crop growth stage

\section{Introduction}

Soil moisture content (SMC) affects a wide range of interactions between earth systems in the soil-vegetation-atmosphere continuum, such as hydrological and biological processes, and is an important driver of material and energy transfer [1-3]. It is also an integral part of the hydrological cycle and it is one of the important parameters describing the processes of the terrestrial hydrological cycle, controlling, to varying degrees, the processes of runoff, evaporation, and infiltration [2,4,5]. In addition, soil moisture has strong spatial and temporal variability [6]. Some scholars classify the variability of soil moisture 
according to the coefficient of variation, which is mainly divided into three categories: weak variability, moderate variability, and strong variability [7]. Based on the coefficient of variation $(\mathrm{CV})$ and standard deviation of soil moisture, the soil layer is divided into four layers: the rapid change layer, active layer, sub-active layer, and relatively stable layer [7]. Therefore, SMC has been a focus of concern for many researchers. The complex process of soil moisture variability is mainly due to the fact that SMC is influenced by several factors [8,9]. These factors include soil properties (particle composition, bulk density, porosity, and organic matter content, etc.) $[10,11]$; rainfall characteristics (rainfall intensity, rainfall amount and rainfall duration, etc.) [12,13]; vegetation type [14,15]; topography (slope direction, slope, and elevation, etc.) [16]; meteorological factors (relative humidity and temperature, etc.) $[17,18]$. Dong et al. [19] investigated the structural similarity and spatial correlation of SMC with soil texture and precipitation at the mesoscale (about $150 \mathrm{~km}$ transect) and found that soil texture has more influence on SMC patterns than precipitation, mainly due to the large spatial variability of precipitation, which has a complex effect on SMC. Kim et al. [20] monitored SMC changes on steep slopes and showed that the distribution of macropores significantly affected SMC changes. In addition, it has been shown that the difference between rainfall and evapotranspiration can largely explain the variability characteristics of SMC in forest ecosystems [21].

Many scholars have started to focus on quantitative analysis of the degree of influence of different factors on SMC, and the most studied site is the Loess Plateau. Much less attention has been given to SMC changes in the Northern Anhui Plain (NAP). The region is a crop-producing area dominated by agricultural crops, and food production is critical. The region is a climate transition zone that is prone to drought or flooding, which indirectly affects crop growth through SMC. Therefore, this paper focuses on the variability and deficit of soil moisture for different crops and soil depths in the NAP. The redundancy analysis (RDA) method is used to study the contribution of meteorological factors, groundwater depth, and crop growth period to SMC in the same period, providing a basis for accurate prediction of dynamic soil characteristics, agricultural irrigation, and crop growth.

\section{Materials and Methods}

\subsection{Description of the Study Area}

In this paper, the Wudaogou Hydrological Experimental Station $\left(117^{\circ} 21^{\prime} \mathrm{E}, 33^{\circ} 9^{\prime} \mathrm{N}\right)$, located in Xinmaqiao Town, Guzhen County, Bengbu City, Anhui Province, was chosen as the study site. It is located in the southern part of the NAP and belongs to the north-south climate transition zone of China. The average annual rainfall in the region is about $890 \mathrm{~mm}$ and is mainly concentrated in June to September. About $62 \%$ of the total annual precipitation falls in this peak period and it is usually of short duration and heavy. The average multi-year water evaporation is about $850 \mathrm{~mm}$, and the average multi-year temperature is about $14{ }^{\circ} \mathrm{C}$. The main soil type is lime concretion black soil (LCBS), which accounts for about $54 \%$ of the total area of the NAP. This area is a shallow groundwater area, and the depth of groundwater depth varies from 1 to $3 \mathrm{~m}$ for many years. The main crops grown are winter wheat, summer maize, and summer soybeans.

\subsection{Soil Physical Properties}

The physical properties of the soil play an important role in the transport of SMC and material. Therefore, the LCBS in the field was selected to measure the physical properties of different soil depths. First, the soil particle gradation at different depths (classified according to international system standards) was measured using the sieve method and the hydrometer method; and a ring knife was then used to take the undisturbed soil and measure the bulk density of different soil depths. From top to bottom, there were a total of 8 soil layers: $0-10 \mathrm{~cm}, 10-20 \mathrm{~cm}, 20-30 \mathrm{~cm}, 30-40 \mathrm{~cm}, 40-50 \mathrm{~cm}, 50-60 \mathrm{~cm}, 60-80 \mathrm{~cm}$, and 80-100 cm. Three undisturbed soils were taken from each layer and brought back to the laboratory to determine the soil water characteristic curves for different soil depths. The soil particle composition of the different soil layers is shown in Table 1. 
Table 1. Particle size distribution for soils with different depths of the lime concretion black soil.

\begin{tabular}{ccccc}
\hline Soil Depth/cm & $\begin{array}{c}\text { Bulk } \\
\text { Density/(g.cm }\end{array}$ & $\begin{array}{c}\text { Clay/\% } \\
\mathbf{( 0 - 0 . 0 0 2} \mathbf{~ m m )}\end{array}$ & $\begin{array}{c}\text { Silt/\% } \\
\mathbf{( 0 . 0 0 2 - 0 . 0 2} \mathbf{~ m m )}\end{array}$ & $\begin{array}{c}\text { Sand/\% } \\
\mathbf{( 0 . 0 2 - 2} \mathbf{~ m m})\end{array}$ \\
\hline $0-20$ & 1.49 & 11.9 & 51.3 & 36.8 \\
$20-40$ & 1.52 & 19.5 & 47.9 & 32.6 \\
$40-60$ & 1.49 & 17.9 & 49.4 & 32.7 \\
$60-80$ & 1.52 & 21.1 & 46.3 & 32.6 \\
$80-100$ & 1.57 & & \\
\hline
\end{tabular}

\subsection{Experimental Design}

The data selected in this paper are the $0-1 \mathrm{~m}(0-10 \mathrm{~cm}, 10-20 \mathrm{~cm}, 20-30 \mathrm{~cm}, 30-40 \mathrm{~cm}$, $40-50 \mathrm{~cm}, 50-60 \mathrm{~cm}, 60-80 \mathrm{~cm}$, and $80-100 \mathrm{~cm}$ ) SMC data during the growth period of winter wheat and summer maize at the Wudaogou Hydrological Experimental Station from 1989 to 2019. To measure the SMC, soil samples were taken from the field at different depths using a soil auger every 5 days (the dates were every 1 and every 6), layered into aluminum boxes, and then taken to the laboratory to dry in an oven at $105^{\circ} \mathrm{C}$ to calculate the SMC at different depths, with additional measurements during the rainy season. The influence of factors on the SMC in different soil layers was also analyzed in conjunction with hydro-meteorological data for the same period, including water surface evaporation, rainfall, sunshine duration, ground temperature, and air temperature (all on a daily scale). Winter wheat is generally sown in mid-October and harvested in late May; summer maize is generally sown in late June and harvested in early October.

\subsection{Analytical Methods}

Classical statistics were used to analyze the variation of SMC at different soil depths. The key parameters were average value, maximum value, minimum value, $\mathrm{CV}$, standard deviation, kurtosis, and skewness. One-way ANOVA was conducted to determine whether there were significant differences between SMC at different soil depths and different growing periods of the crop (Statistics based on year). Multiple comparison analysis was done using Duncan's method.

In order to analyze the contribution of each meteorological factor to the SMC of different crops and different soil depths, RDA analysis was used to rank the SMC of different crops at different depths [22]. The meteorological factors include nine types of rainfall, evaporation, groundwater depth of burial, average wind speed, average ground temperature $(0-80 \mathrm{~cm})$, and sunshine duration. All of them are actual measured values and also include different growing periods of crops. During RDA analysis, two matrices need to be inputted, one is the SMC matrix of different soil depths, and the other is a matrix composed of environmental factors. To determine the relationship between SMC and environmental factors, CANOCO for Windows 5.0 software was used to perform RDA analysis of SMC and environmental factors.

The CV reflects the active degree of soil moisture at different soil depths. The larger the value, the more active and the more frequent the water exchange [17]. It was calculated by the following equation:

$$
\begin{gathered}
\mathrm{CV}=\frac{s}{\bar{x}} \times 100 \% \\
s=\sqrt{\frac{1}{n-1} \sum_{i=1}^{n}\left(x_{i}-\bar{x}\right)^{2}}
\end{gathered}
$$

where $n$ is the number of samples, $x_{i}$ is the $i$ th soil moisture content $(\%), \bar{x}$ is the average soil moisture content $(\%)$.

After the moisture characteristic curves of different soil layers were determined, three fitting models were used to fit the soil moisture characteristic curves and the goodness of fit of the models was measured using the correlation coefficient $\left(R^{2}\right)$ and root mean 
square error (RMSE). The three models were calculated as follows: the Van Genuchten $(\mathrm{V}-\mathrm{G})$ model was [23]:

$$
\frac{\theta-\theta_{r}}{\theta_{s}-\theta_{r}}=\left(\frac{1}{1+(\alpha|h|)^{n}}\right)^{1-1 / n}
$$

where $\theta$ is the volumetric water content of the soil (\%), $\theta_{r}$ sand $\theta_{s}$ are residual volumetric water content and saturated volumetric water content of the soil (\%), respectively, $h$ is the substrate potential of the soil $(\mathrm{cm}), \alpha$ is the reciprocal of the soil intake value $\left(\mathrm{cm}^{-1}\right), n$ is the model curve shape parameter.

The Gregory model was [24]:

$$
\frac{\theta-\theta_{r}}{\theta_{s}-\theta_{r}}=\left(\frac{1}{1+\left(\varepsilon^{b}|h|\right)^{n}}\right)^{1-1 / n}
$$

where $\varepsilon$ is the soil porosity; $b$ is the fitting parameter.

The Brooks-Corey (B-C) model was [25]:

$$
\frac{\theta-\theta_{r}}{\theta_{s}-\theta_{r}}=(\alpha|h|)^{-\lambda}
$$

where $\lambda$ is the fitting parameter.

The calculation formula of the average SMC of a certain soil depth during the growth period of different crops was:

$$
\overline{w_{i j}}=\frac{1}{N} \sum_{k=1}^{N} w_{i j k}
$$

where $w_{i j k}$ is the soil volumetric water content in the $k$ th day of different crop growth periods $i$ and soil depth $j(\%), N$ is the total number of days in the growth period $i$, and soil depth $j$ in the long-term sequence from 1989 to 2019.

Soil water storage (SWS, $\mathrm{mm}$ ) represents the amount of water stored in a certain thickness of soil. It was calculated as follows [26]:

$$
\mathrm{SWS}=\sum_{i=1}^{m} \theta_{i} \times B D_{i} \times h_{i}
$$

where $\theta_{i}, B D_{i}$ and $h_{i}$ is the mass water content of the ith layer of soil, the soil capacity, and the thickness of the soil layer, respectively $(\%),\left(\mathrm{g} \cdot \mathrm{cm}^{-3}\right), \mathrm{mm}$.

The soil water deficit degree (SWD, \%) is the degree of soil water deficit for vegetation growth. When the deficit degree is large, it will have an impact on crop yields and seriously cause crop death [27]. It was defined as [28]:

$$
\begin{gathered}
D_{a}=F-\text { SWS } \\
\mathrm{SWD}=\frac{D_{a}}{\sum_{i=1}^{m} F_{i} \times h_{i}} \times 100 \%
\end{gathered}
$$

where $D_{a}$ is the soil water deficit $(\mathrm{mm}), F_{i}$ is the field water holding capacity of the $i$ th soil layer (\%). In this paper, the field water holding capacity refers to the soil water content at the suction of $330 \mathrm{~cm}[29]$.

\section{Results and Discussion}

\subsection{Statistical Analysis of Soil Hydraulic Parameters and SMC}

Figure 1 shows the results of fitting the soil moisture characteristic curve of LCBS, and it was found that the soil moisture characteristic curve could be well fitted using the V-G model, Gregory model, and B-C model, and the coefficient of determination $\mathrm{R}^{2}>0.99$. However, comparing the three fitting models, it was found that the RMSE 
obtained by the Gregory model was the smallest. In addition, the analysis of the fitting results for different soil depths revealed that the Gregory model had better fitting results, and the $R^{2}$ for all three fitting models was greater than 0.95 . The range of RMSE for the V-G model was $0.0007-0.0022 \mathrm{~cm}^{3} \cdot \mathrm{cm}^{-3}$, the range of RMSE for the Gregory model was $0.0009-0.0021 \mathrm{~cm}^{3} \cdot \mathrm{cm}^{-3}$, and the range of RMSE for the B-C model was $0.0010-0.0027 \mathrm{~cm}^{3} \cdot \mathrm{cm}^{-3}$. Therefore, the Gregory model was used to fit the soil moisture characteristic curves, and the fitted parameters are shown in Table 2.

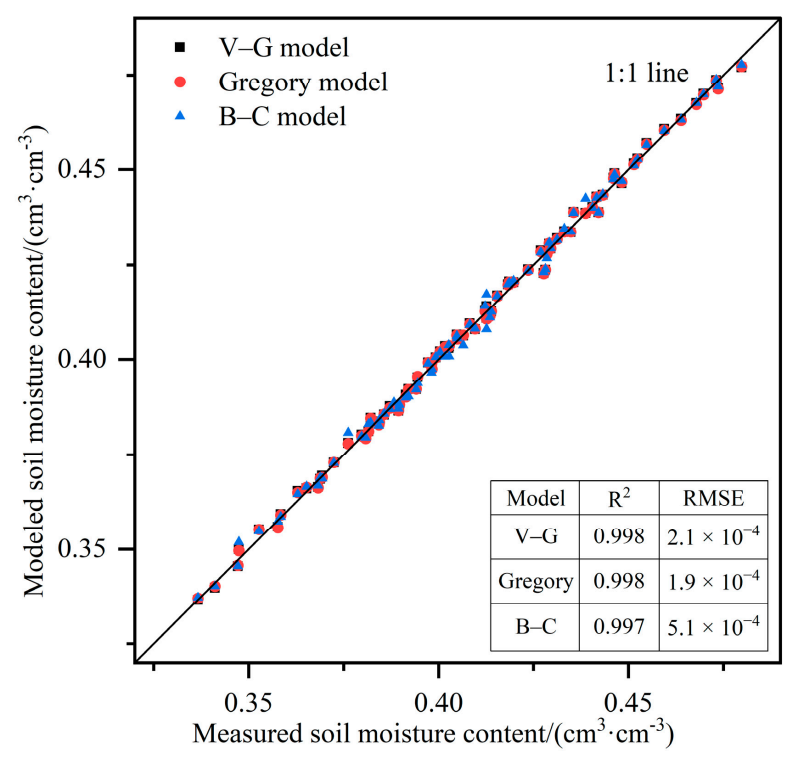

Figure 1. Comparison of modeled soil moisture content and measured soil moisture content.

Table 2. Statistical results of soil hydraulics parameters.

\begin{tabular}{cccccc}
\hline $\begin{array}{c}\text { Soil } \\
\text { Depth/cm }\end{array}$ & $\begin{array}{c}\text { Residual Water } \\
\text { Content/\% }\end{array}$ & $\begin{array}{c}\text { Saturated Water } \\
\text { Content/\% }\end{array}$ & $\mathbf{b}$ & $\mathbf{n}$ & $\mathbf{R}^{\mathbf{2}}$ \\
\hline $0-10$ & 1.9 & 45.2 & 5.4837 & 1.045 & 0.997 \\
$10-20$ & 8.7 & 42.5 & 0.0012 & 1.031 & 0.994 \\
$20-30$ & 10.5 & 50.7 & 0.0002 & 1.025 & 0.985 \\
$30-40$ & 10.0 & 51.0 & 0.0001 & 1.022 & 0.989 \\
$40-50$ & 10.3 & 47.6 & 0.0001 & 1.022 & 0.993 \\
$50-60$ & 11.0 & 44.8 & 0.0847 & 1.021 & 0.972 \\
$60-80$ & 8.3 & 42.5 & 0.7835 & 1.021 & 0.995 \\
$80-100$ & 4.3 & 41.5 & 5.7281 & 1.024 & 0.988 \\
\hline
\end{tabular}

The results of SMC statistics for different soil depths of wheat and maize are presented in Table 3. SMC at different depths showed wheat $>$ maize, and SMC between different crops showed significant differences $(p<0.01)$, demonstrating that crop type is an important influence on soil moisture [30]. For wheat, the SMC at different depths ranged from 4.1 to $35.6 \%$, and the SMC showed an increase followed by a decrease with increasing soil depth The SMC at the depth of $0-10 \mathrm{~cm}$ was the lowest and significantly lower than the SMC at the depth of 20-100 cm, which was $(19.6 \pm 4.9) \%$; the SMC at the depth of $40-50 \mathrm{~cm}$ was the highest and significantly higher than the other soil layers (except $30-40 \mathrm{~cm}$ ), which was $(24.9 \pm 3.62) \%$. For maize, the SMC at different depths ranged from 2.7 to $39.0 \%$, and the SMC showed an increase followed by a decrease with increasing soil depth. The SMC at the depth of $0-10 \mathrm{~cm}$ was the lowest and significantly lower than the SMC at the depth of $20-100 \mathrm{~cm}$, which was $(18.3 \pm 5.18) \%$; the SMC at the depth of $30-40 \mathrm{~cm}$ was the highest and significantly higher than the other soil layers (except $40-50 \mathrm{~cm}$ ), which was $(23.5 \pm 3.81) \%$. 
Table 3. Statistical characteristics of soil moisture content of different crops.

\begin{tabular}{|c|c|c|c|c|c|c|c|c|}
\hline \multirow[b]{2}{*}{ Crop Type } & \multirow{2}{*}{$\begin{array}{c}\text { Soil } \\
\text { Depth/cm }\end{array}$} & \multicolumn{7}{|c|}{ Statistical Variables/\% } \\
\hline & & $\begin{array}{l}\text { Minimum } \\
\text { Value }\end{array}$ & $\begin{array}{c}\text { Maximum } \\
\text { Value }\end{array}$ & $\begin{array}{l}\text { Mean } \\
\text { Value }\end{array}$ & $\begin{array}{c}\text { Standard } \\
\text { Deviation }\end{array}$ & Skewness & Kurtosis & $\begin{array}{l}\text { Coefficient } \\
\text { of Variation }\end{array}$ \\
\hline \multirow{8}{*}{ Wheat } & $0-10$ & 4.1 & 38.4 & $19.6 \mathrm{Ae}$ & 4.90 & 0.00 & 0.78 & 25.1 \\
\hline & $10-20$ & 7.8 & 31.7 & 19.9Ae & 4.07 & -0.32 & 0.01 & 20.5 \\
\hline & $20-30$ & 9.0 & 33.6 & 21.6Ad & 4.59 & -0.13 & -0.27 & 21.2 \\
\hline & $30-40$ & 11.1 & 35.6 & 24.7Aa & 4.12 & -0.48 & -0.21 & 16.7 \\
\hline & $40-50$ & 13.1 & 35 & $24.9 \mathrm{Aa}$ & 3.62 & -0.56 & 0.11 & 14.6 \\
\hline & $50-60$ & 11.9 & 32.7 & 23.9Ab & 3.23 & 0.21 & 0.23 & 13.5 \\
\hline & $60-80$ & 12.2 & 30.9 & $22.8 \mathrm{Ac}$ & 2.93 & -0.60 & 0.16 & 12.9 \\
\hline & $80-100$ & 12.2 & 31.7 & 22.0Ad & 2.71 & -0.64 & 0.31 & 12.3 \\
\hline \multirow{8}{*}{ Maize } & $0-10$ & 2.7 & 39.0 & $18.3 \mathrm{Be}$ & 5.18 & -0.26 & 0.71 & 28.4 \\
\hline & $10-20$ & 4.9 & 30.0 & $18.8 \mathrm{Be}$ & 3.89 & -0.47 & 0.81 & 20.7 \\
\hline & $20-30$ & 6.1 & 33.1 & $20.9 \mathrm{BC}$ & 4.27 & -0.37 & 0.58 & 20.4 \\
\hline & $30-40$ & 11.1 & 32.3 & $23.5 \mathrm{Ba}$ & 3.81 & -0.61 & 0.09 & 16.3 \\
\hline & $40-50$ & 12.5 & 31.8 & $23.1 \mathrm{Ba}$ & 3.55 & 0.46 & 5.46 & 15.3 \\
\hline & $50-60$ & 10.8 & 30.7 & $22.2 \mathrm{Bb}$ & 3.37 & -0.27 & 0.16 & 15.2 \\
\hline & $60-80$ & 11.6 & 31.7 & $21.0 \mathrm{BC}$ & 3.17 & 0.58 & 5.46 & 15.1 \\
\hline & 80-100 & 12.0 & 30.3 & $20.2 \mathrm{Bd}$ & 2.88 & -0.02 & 0.01 & 14.3 \\
\hline
\end{tabular}

Note: Lowercase letters indicate significant differences between different depths of the same crop, $p<0.05$; uppercase letters indicate significant differences between different crops, $p<0.01$.

The standard deviation and CV of the SMC of different crops showed a decrease with increasing depth. It indicates that shallow soil water is more susceptible to external factors, such as human activities, rainfall, evaporation, and that the influence of shallow crop roots results in the greater spatial variability of SMC [31]. The CV of SMC at 50-100 cm depth is small, and it is less affected by external disturbances and has strong stability. As the depth increases, the soil water becomes more stable with time, and the degree of fluctuation is smaller $[8,32]$. However, compared with maize, the variation of the standard deviation and the CV of the SMC in wheat fields is more complex, and there is no better change law. The CV of SMC ranges from 20 to $30 \%$ for different crops at $0-30 \mathrm{~cm}$ depth, and from 10 to $20 \%$ at $30-100 \mathrm{~cm}$ depth. According to the study on soil stratification by Chen et al. [7] and Yang et al. [33], it can be found that $0-30 \mathrm{~cm}$ belongs to the active layer and 30-100 cm belongs to the sub-active layer in this area. In general, soil water at different depths in the study area belonged to a moderate degree of variability $(10 \%<\mathrm{CV}<100 \%)$ [7]. For wheat and maize, the regularity of skewness and kurtosis of SMC between different soil layers is not obvious, but it is left-biased, and the soil water content of the maize field shows higher kurtosis.

\subsection{Soil Water Deficit Status of Different Vegetation Types}

Previous studies have shown that the root length and root mass density of winter wheat are mainly concentrated in the upper layer, within the $0-50 \mathrm{~cm}$ soil layer, accounting for 57.7 and $66.7 \%$, respectively [34], while the $0-60 \mathrm{~cm}$ soil depth is the active area of summer maize root growth [35]. Therefore, the entire soil profile is divided into two layers to study the SWS and SWD; 0-60 cm and 60-100 cm, respectively.

It can be seen from Table 4 that in different wheat growth periods, the SMC of $0-100 \mathrm{~cm}$ is the largest in the tillering-wintering period, which is $(23.7 \pm 2.16) \%$. It is the smallest in the heading-mature period, which is $(19.2 \pm 3.12) \%$. The heading-mature period is significantly different from other growth periods $(p<0.05)$. The average daily SWS shows the same change characteristics. The maximum average daily deficit was $118.1 \mathrm{~mm}$ $(0-100 \mathrm{~cm})$ during the grouting-mature period; the minimum average daily deficit was $50.5 \mathrm{~mm}(0-100 \mathrm{~cm})$, which occurred during the tillering-wintering period of wheat. The main reason is that during the tillering-wintering period of wheat, the plant growth is weak and the water demand is small, and as the crop grows, the water demand gradually 
increases [36]. During the growth period of corn, the SMC and daily water storage at different depths of the soil layer changed little, and there was no significant difference. The daily soil water deficit of maize ranged from 71 to $96 \mathrm{~mm}$.

Table 4. Soil moisture status during different growing periods.

\begin{tabular}{|c|c|c|c|c|c|c|c|c|c|c|}
\hline \multirow{2}{*}{$\begin{array}{l}\text { Crop } \\
\text { Type }\end{array}$} & \multirow{2}{*}{$\begin{array}{l}\text { Growth } \\
\text { Period }\end{array}$} & \multicolumn{3}{|c|}{ Average Soil Moisture Content/\% } & \multicolumn{3}{|c|}{ Average Daily Water Storage/mm } & \multicolumn{3}{|c|}{ Average Daily Deficit/mm } \\
\hline & & $0-60 \mathrm{~cm}$ & $60-100 \mathrm{~cm}$ & $0-100 \mathrm{~cm}$ & $0-60 \mathrm{~cm}$ & $60-100 \mathrm{~cm}$ & $0-100 \mathrm{~cm}$ & $0-60 \mathrm{~cm}$ & $60-100 \mathrm{~cm}$ & $0-100 \mathrm{~cm}$ \\
\hline \multirow{4}{*}{ Wheat } & $\begin{array}{l}\text { Emergence- } \\
\text { tillering } \\
\text { period }\end{array}$ & $23.0 \pm 2.86$ & $23.1 \pm 2.38$ & $23.0 \pm 2.57$ & $207.8 \pm 20.50$ & $142.4 \pm 11.67$ & $350.2 \pm 29.36$ & 45.5 & 16.9 & 62.4 \\
\hline & $\begin{array}{l}\text { Tillering- } \\
\text { wintering } \\
\text { period }\end{array}$ & $23.8 \pm 2.45$ & $23.5 \pm 2.13$ & $23.7 \pm 2.16$ & $216.2 \pm 15.40$ & $145.9 \pm 9.17$ & $362.1 \pm 22.46$ & 37.1 & 13.4 & 50.5 \\
\hline & $\begin{array}{l}\text { Regreening- } \\
\text { jointing } \\
\text { period }\end{array}$ & $22.4 \pm 2.90$ & $23.0 \pm 2.17$ & $22.6 \pm 2.55$ & $203.2 \pm 18.21$ & $143.0 \pm 10.15$ & $346.2 \pm 27.00$ & 50.1 & 16.3 & 66.4 \\
\hline & $\begin{array}{l}\text { Heading- } \\
\text { mature } \\
\text { period }\end{array}$ & $19.1 \pm 3.43$ & $19.3 \pm 2.82$ & $19.2 \pm 3.12$ & $173.8 \pm 21.94$ & $120.7 \pm 12.75$ & $294.5 \pm 33.52$ & 79.5 & 38.6 & 118.1 \\
\hline \multicolumn{2}{|c|}{ Whole growth period } & $22.4 \pm 4.67$ & $22.4 \pm 2.85$ & $22.4 \pm 4.30$ & $202.2 \pm 27.80$ & $139.2 \pm 17.51$ & $341.4 \pm 43.96$ & 51.1 & 20.1 & 71.2 \\
\hline \multirow{4}{*}{ Maize } & $\begin{array}{l}\text { Seeding- } \\
\text { emergence } \\
\text { period }\end{array}$ & $21.2 \pm 3.29$ & $20.0 \pm 3.12$ & $20.9 \pm 3.08$ & $190.3 \pm 20.14$ & $126.8 \pm 16.13$ & $317.1 \pm 32.27$ & 63.0 & 32.5 & 95.5 \\
\hline & $\begin{array}{l}\text { Jointing- } \\
\text { booting } \\
\text { period }\end{array}$ & $20.9 \pm 3.36$ & $21.0 \pm 2.94$ & $20.9 \pm 3.12$ & $193.6 \pm 21.57$ & $135.1 \pm 15.72$ & $328.6 \pm 35.93$ & 59.7 & 24.2 & 83.9 \\
\hline & $\begin{array}{l}\text { Heading- } \\
\text { flowering } \\
\text { period }\end{array}$ & $21.5 \pm 2.75$ & $20.7 \pm 2.71$ & $21.3 \pm 2.65$ & $195.4 \pm 20.24$ & $130.0 \pm 16.12$ & $325.4 \pm 35.04$ & 57.9 & 29.3 & 87.2 \\
\hline & $\begin{array}{l}\text { Grouting- } \\
\text { mature } \\
\text { period }\end{array}$ & $21.1 \pm 3.39$ & $21.5 \pm 2.89$ & $21.2 \pm 3.02$ & $191.4 \pm 24.68$ & $135.5 \pm 14.99$ & $327.0 \pm 35.91$ & 61.9 & 23.8 & 85.7 \\
\hline \multicolumn{2}{|c|}{ Whole growth period } & $21.1 \pm 4.53$ & $20.7 \pm 3.07$ & $21.0 \pm 4.23$ & $190.6 \pm 29.18$ & $129.9 \pm 19.28$ & $320.4 \pm 44.67$ & 62.8 & 29.4 & 92.2 \\
\hline
\end{tabular}

Note: The data in the table are mean \pm standard deviation.

Comparing the soil moisture status of maize and wheat, it was found that the SMC and daily SWS of both $0-60 \mathrm{~cm}$ and $60-100 \mathrm{~cm}$ wheat during the whole growth period were slightly larger than that of maize. The average daily soil water deficit of 0-60 cm soil layer is about twice that of $60-100 \mathrm{~cm}$, mainly because the depth is the active area of crop roots, and the roots grow vigorously and absorb a lot of water. It has also been confirmed that root water uptake is the main way to consume SMC [15,37]. In addition, the daily SWS during the whole reproductive period of wheat is higher than that of maize, and the daily SWD is smaller than that of maize during the whole growth period in different depths of the soil. However, maize grows in the rainy season, and rainfall replenishes soil water. From the site, it shows that the water consumed by maize growth and the water absorbed by the surrounding area is far more than that of wheat.

\subsection{Effect of Different Growth Periods on SMC}

The variation of SMC at different soil depths during each growth period of wheat is shown in Figure 2. During the same growth period, the SMC showed a trend of increasing and then decreasing with increasing soil depth and reached the maximum at $40-50 \mathrm{~cm}$. The SMC of 30-60 cm was significantly higher than that of other soil layers during the emergence-tillering period. During the tillering-mature stage, the SMC at $30-50 \mathrm{~cm}$ was significantly higher than other soil layers. Under the same soil depth, the SMC showed a changing pattern of increasing and then decreasing with crop growth, reaching the maximum at the tillering-wintering period and the minimum at the heading-mature period. Moreover, the SMC at different soil depths during the heading-mature period was significantly lower than during other growth periods. The main reason is that the water demand in the seedling stage is small, and the soil water has mainly evaporated and infiltrated. After jointing, filling, and heading, etc., wheat grows rapidly, and the water demand increases significantly, resulting in a significantly lower SMC in the headingmature period than other growth periods [38]. 


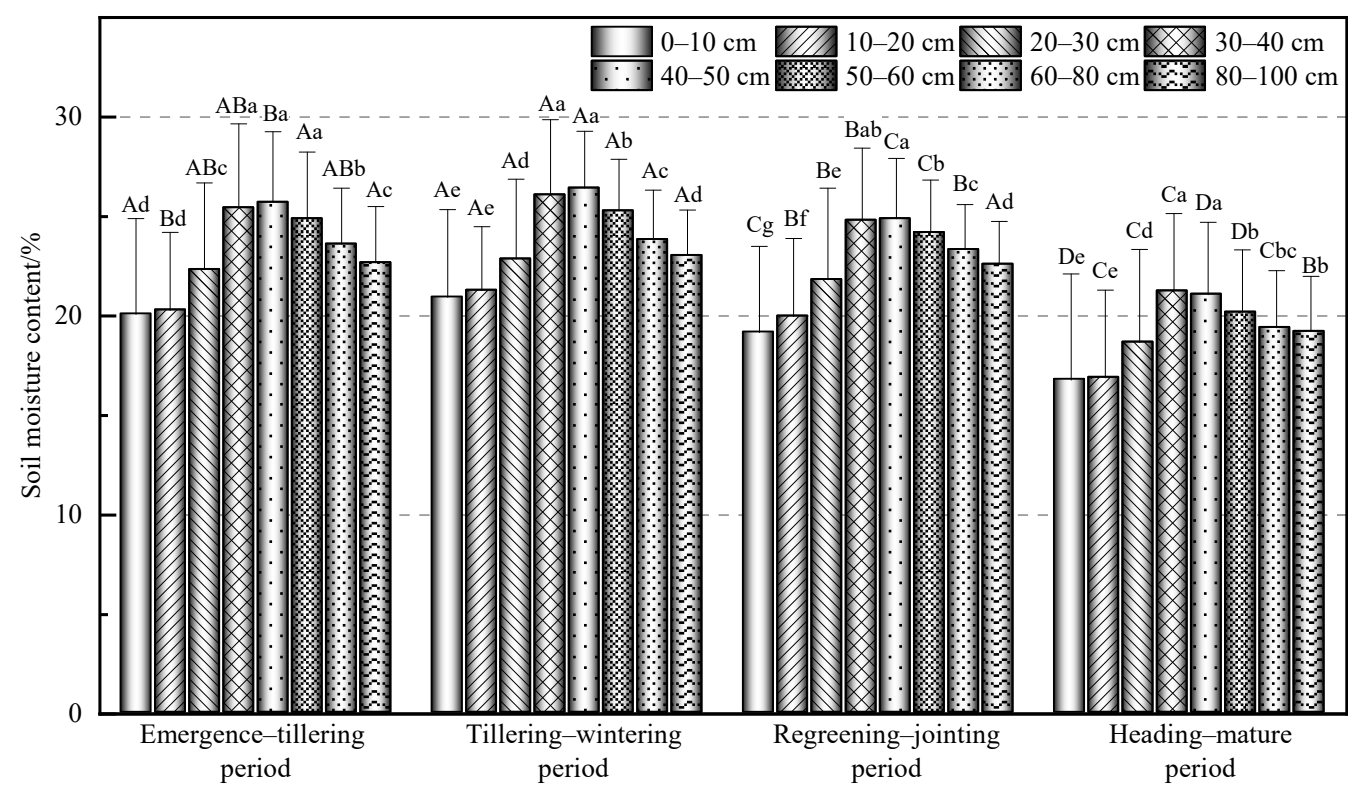

Figure 2. Effect of different growth periods of wheat on soil moisture content (Lowercase letters represent significant differences in soil moisture content at the 0.05 level for each soil layer, and uppercase letters represent significant differences in soil water content at the 0.05 level for each growing period. Same as below).

From Figure 3, it can be seen that the SMC of maize showed a changing pattern of increasing and then decreasing with increasing soil depth during the same growth period, which is basically the same as the changing pattern of wheat. However, the maximum SMC in different growth periods of maize occurred at the depth of 30-40 cm soil layer. The SMC of 30-50 cm was significantly higher than other soil layers during the four fertility periods. At the same depth of the soil layer, there is little change in SMC in different growth periods. Except for 0-10 $\mathrm{cm}$ and $60-80 \mathrm{~cm}$, there was no significant difference in SMC at different fertility stages in each soil layer. This is mainly because the soil water demand increases with the growth of the crop. The growing period of maize is from June to September (rainy season), which provides sufficient water for the growth of maize so that the difference in SMC between different fertility periods in the same soil depth is not significant [38].

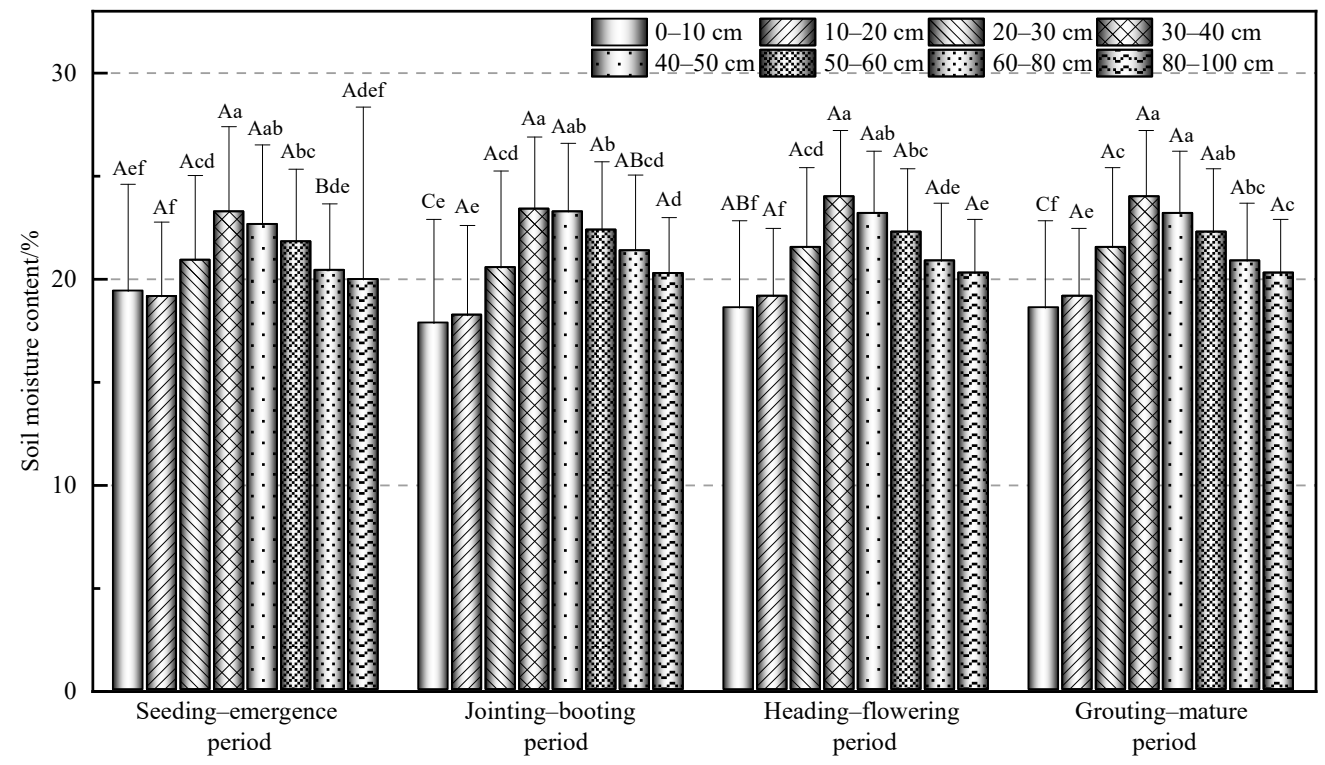

Figure 3. Effect of different growth periods of maize on soil moisture content. 


\subsection{The Relationship between SMC and Influencing Factors}

For wheat, groundwater depth, air temperature, water vapor pressure difference, and ground temperature were significantly negatively correlated with SMC $(p<0.001)$ (Figure 4). The most relevant is the ground temperature, followed by the water vapor pressure difference. For maize, there was a significant negative correlation between groundwater depth and SMC $(p<0.001)$ and a significant positive correlation between relative humidity and SMC $(p<0.001)$ (Figure 4$)$. It can be found that the factors affecting the soil moisture in relation to the crop are distinct for the two different seasons. However, the groundwater depth is an important factor affecting soil moisture, which is highly related to the area being a shallow groundwater burial zone. In addition, other influencing factors have different effects on SMC, which is closely related to the growing environment.
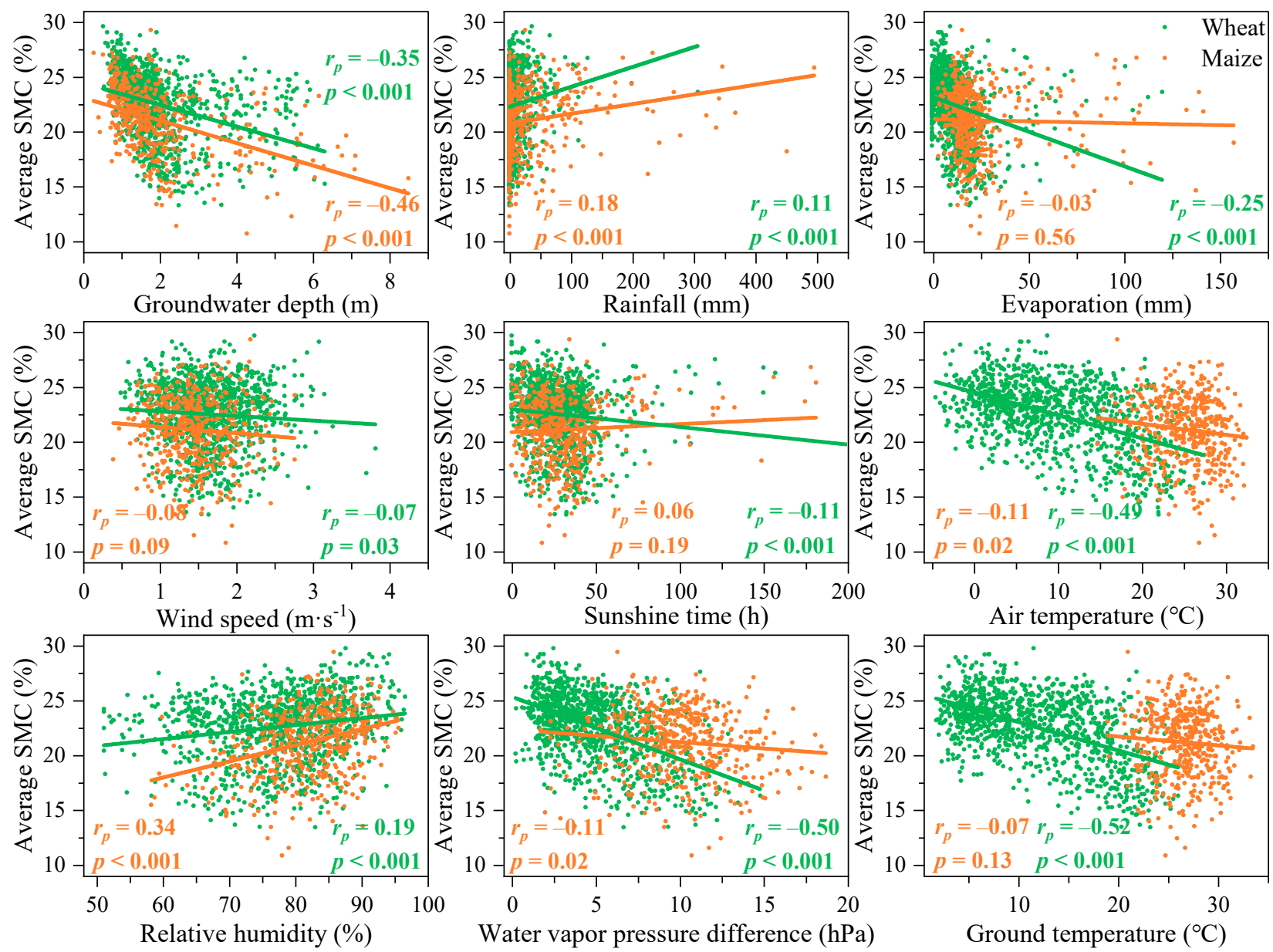

Figure 4. Relationship between average soil moisture content and influencing factors.

By analyzing the correlation between meteorological factors, groundwater depth, crop growth period, and SMC of different layers, it is found that the correlation coefficients of air temperature with ground temperature and water vapor pressure difference are 0.98 $(p<0.01)$ and $0.84(p<0.01)$, respectively. We also removed air temperature to analyze the influence of the remaining nine factors on SMC. To explore the contribution of different influencing factors on SMC, RDA analysis was used for this study. In our study, 1 represents the wheat (maize) emergence-tillering period (seeding-emergence period); 2 represents the wheat (maize) tillering-wintering period (jointing-booting period); 3 represents the wheat (maize) regreening-jointing period (heading-flowering period); and 4 represents the wheat (maize) heading-mature period (grouting-mature period). Before the RDA analysis, a detrended correspondence analysis (DCA) was first performed on the SMC of wheat and 
maize land, and it was found that the maximum gradient length was less than 3 , indicating that the contribution of influencing factors to SMC could be analyzed by RDA.

Through 999 Monte Carlo random permutation tests, each ranking axis was tested one by one, and it was found that the first and second ranking axes of wheat and maize reached extremely significant levels $(p<0.01)$. Table 5 presents the correlation coefficients between the first two ranking axes and the influencing factors after analysis by RDA. The two ranking axes for wheat explained 91.1 and $7.3 \%$ of the total soil moisture-influence factor, respectively, and the first two ranking axes cumulatively explained $98.4 \%$ of the soil moisture-influence factor relationship. The two ranking axes for maize explained 83.1 and $13.5 \%$ of the total soil moisture-influence factor, respectively, and the first 2 ranking axes cumulatively explained $96.6 \%$ of the soil moisture-influence factor relationship. It shows that whether it is wheat or maize, the first two ranking axes reflect most of the information about the relationship between soil moisture and influencing factors, and the correlation coefficient of influencing factors on the first ranking axis is greater. In the case of wheat planting, the relationship between ground temperature and the first ordination axis is the closest, followed by water vapor pressure difference, growth period, and groundwater depth. It shows that the first sort axis mainly reflects the gradient changes of SMC with ground temperature, water vapor pressure difference, growth period, and groundwater depth. The second sort axis mainly reflects the gradient change of SMC with relative humidity and rainfall. In the case of maize planting, the first ranking axis mainly responds to the gradient of soil moisture with groundwater depth, relative humidity, and rainfall. The 2nd ranking axis mainly responds to the gradient of soil moisture with the growing period, groundwater depth, and sunshine time.

Table 5. Correlation coefficients between influencing factors wheat and maize land and the first 2 axes of the RDA analysis ranking.

\begin{tabular}{ccccc}
\hline & \multicolumn{2}{c}{$\begin{array}{c}\text { Wheat RDA Analysis } \\
\text { Sorting Axis }\end{array}$} & \multicolumn{2}{c}{$\begin{array}{c}\text { Maize RDA Analysis } \\
\text { Sorting Axis }\end{array}$} \\
\cline { 2 - 5 } Influencing Factors & Axis1 & Axis2 & Axis1 & Axis2 \\
& -0.423 & -0.148 & -0.012 & -0.211 \\
Growth period & -0.347 & -0.045 & 0.470 & 0.198 \\
Groundwater depth & 0.126 & -0.193 & -0.226 & 0.147 \\
Rainfall & -0.249 & 0.061 & 0.008 & 0.042 \\
Evaporation & -0.066 & -0.008 & 0.084 & -0.042 \\
Wind speed & -0.118 & 0.160 & -0.051 & -0.200 \\
Sunshine time & -0.499 & 0.002 & 0.137 & -0.163 \\
Water vapor pressure difference & 0.207 & -0.339 & -0.372 & 0.164 \\
Relative humidity & -0.510 & -0.127 & 0.075 & -0.113 \\
Ground temperature & & & & \\
Cumulative rate of change of & 91.1 & 98.4 & 83.1 & 96.6 \\
soil moisture-influence factor & & & & \\
correlation/\% & & & & \\
\hline
\end{tabular}

It can be seen from the RDA sequence diagram that the factors affecting soil moisture are different for different vegetation and depths (Figure 5). For wheat, relative humidity and rainfall were positively correlated with $0-40 \mathrm{~cm}$ SMC, the correlation decreased with increasing depth, and the correlation with $40-100 \mathrm{~cm}$ SMC was very small. Rainfall was not the only factor affecting soil water [39]. Evaporation was negatively correlated with SMC from 0 to $40 \mathrm{~cm}$, and the correlation weakened with increasing depth, indicating that soil moisture in the surface layer was more influenced by rainfall and evaporation, a finding that was consistent with the previous results [40]. Meanwhile, the growth period, ground temperature, and groundwater depth were more correlated with 40-100 cm SMC, which showed a negative correlation. As the roots of growing crops absorb deep soil moisture, groundwater recharges deep soil moisture, resulting in changes in soil moisture. Combined with Table 6, it was found that the contributions of ground temperature, groundwater depth, relative humidity, and growing period to soil moisture variation were 51.5, 16.9, 13, 
and $8.9 \%$, respectively. For maize, groundwater depth and relative humidity had a greater effect on SMC. Water vapor pressure difference, relative humidity, and rainfall mainly affect 0-30 cm SMC. Water vapor pressure difference has a negative correlation with soil moisture, while relative humidity and rainfall have a positive correlation with soil moisture. Groundwater depth significantly affected SMC from 30 to $100 \mathrm{~cm}$, and groundwater depth was negatively correlated with soil moisture, and the correlation coefficient was the largest. The main reasons are as follows: the growth period of maize is from June to October each year when the temperature is high and there is the most daylight, which increases the evaporation of the soil. At the same time, this period is also the rainy season in the area, with heavy rainfall and shallow groundwater, which has a strong recharge effect on soil moisture. Chen and $\mathrm{Hu}$ [41] pointed out that groundwater has an impact on soil moisture at the roots of crops, which in turn affects surface evaporation; this effect has a great influence when the groundwater depth is shallow. Combined with Table 6, it was found that the contribution rates of groundwater depth, relative humidity, water vapor pressure difference, and rainfall to soil moisture changes were 59.6, 19.8, 5.7, and 4.1\%, respectively. This is consistent with the results obtained in Figure 4.
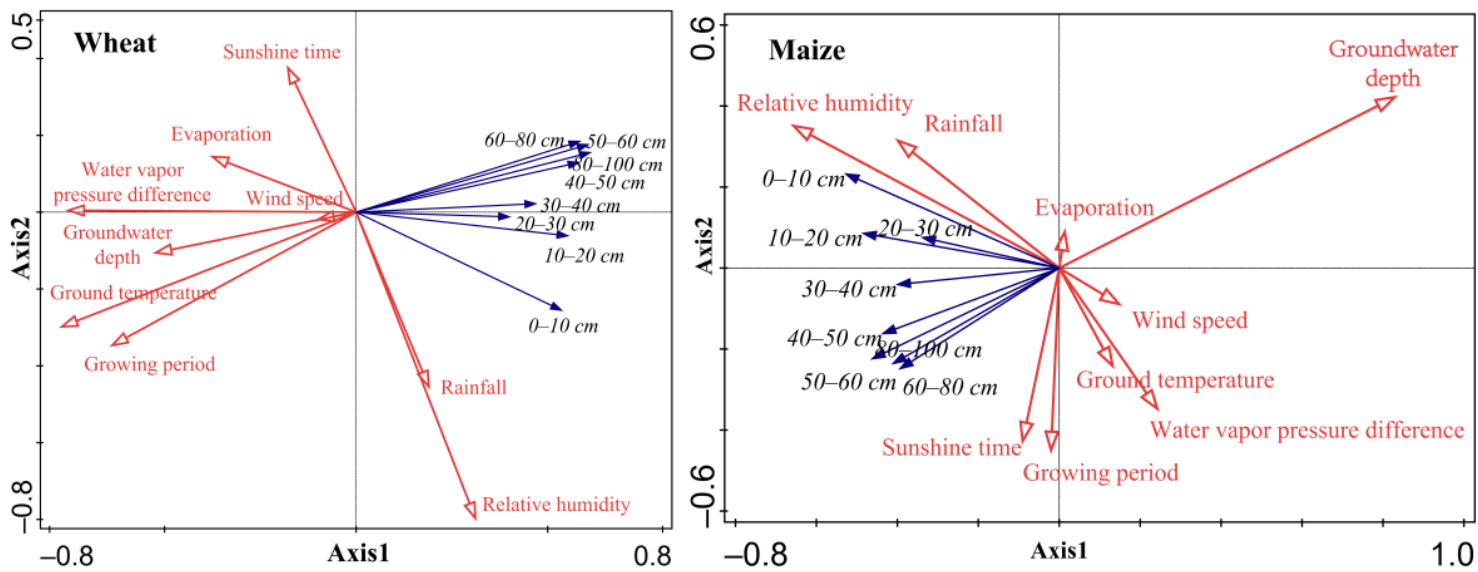

Figure 5. Soil moisture content of wheat and maize and the influencing factors RDA analysis ranking.

Table 6. Forward selection of influencing factors in RDA analysis and Monte Carlo test.

\begin{tabular}{|c|c|c|c|c|c|c|c|}
\hline \multirow[b]{2}{*}{ Influencing Factors } & \multicolumn{3}{|c|}{ Wheat } & \multirow[b]{2}{*}{ Influencing Factors } & \multicolumn{3}{|c|}{ Maize } \\
\hline & $\begin{array}{c}\text { Interpretation } \\
\text { Rate } / \%\end{array}$ & $\begin{array}{c}\text { Contribution } \\
\text { Rate } \%\end{array}$ & $p$ & & $\begin{array}{c}\text { Interpretation } \\
\text { Rate/\% }\end{array}$ & $\begin{array}{c}\text { Contribution } \\
\text { Rate/\% }\end{array}$ & $p$ \\
\hline Ground temperature & 16.7 & 54.5 & 0.001 & Groundwater depth & 14.1 & 59.6 & 0.001 \\
\hline Groundwater depth & 5.3 & 17.3 & 0.001 & Sunshine time & 0.8 & 3.4 & 0.005 \\
\hline Relative humidity & 3.4 & 11.1 & 0.001 & Rainfall & 1 & 4.1 & 0.005 \\
\hline Growth period & 2.7 & 8.7 & 0.001 & Relative humidity & 4.7 & 19.8 & 0.001 \\
\hline Rainfall & 1.1 & 3.7 & 0.001 & $\begin{array}{l}\text { Water vapor pressure } \\
\text { difference }\end{array}$ & 1.3 & 5.7 & 0.001 \\
\hline Evaporation & 0.6 & 2.1 & 0.001 & Ground temperature & 0.7 & 2.8 & 0.01 \\
\hline $\begin{array}{l}\text { Water vapor pressure } \\
\text { difference }\end{array}$ & 0.5 & 1.6 & 0.001 & Growth period & 0.8 & 3.4 & 0.009 \\
\hline Sunshine time & 0.3 & 0.9 & 0.009 & Evaporation & 0.1 & 0.6 & 0.434 \\
\hline Wind speed & $<0.1$ & 0.2 & 0.531 & Wind speed & 0.1 & 0.5 & 0.529 \\
\hline
\end{tabular}

It can be seen that the factors that affect the variability of soil moisture under different crops are different, and mainly related to the growth period of the two crops. Wheat and maize grow at different times. The growing period of wheat is from October to June, when there is low rainfall and low temperatures. In contrast, the growing period of maize is from June to October. During this period, there is a lot of rainfall, high temperatures, shallow groundwater depth, and large fluctuations in soil moisture. This is consistent with the changes in the CV of SMC in wheat and maize fields in Table 3. But there are many main factors affecting soil water changes, and different scholars have different 
opinions [17]. Han et al. [42] concluded that the main meteorological factors affecting SMC are temperature, solar radiation, and saturated water vapor pressure difference. Li et al. [43] found that rainfall and temperature are the main factors affecting soil water changes, which are partly consistent with the results obtained in this paper. Wang and Franz [44] believed that soil water changes are more affected by soil hydraulic parameters than meteorological factors. Biswas and $\mathrm{Si}$ [45] recorded that topography (slope, aspect, and altitude, etc.) is also an important factor affecting soil water variability. The topography changes the lateral flow of soil water and surface runoff, causing soil water to redistribute spatially. In addition, some scholars pointed out that the research scale and land use type also affect soil water changes [39,46]. This paper analyzes the factors that affect soil water changes at the point scale and farmland conditions. In the future, we need to extend the point to the surface and study the effects of different land-use types on SMC from the slope and watershed scales.

\section{Conclusions}

SMC is an important variable in understanding hydrological cycle processes. We analyzed the dynamic characteristics and the influencing factors in SMC based on the long series of field-measured SMC data from 1989-2019 at the Wudaogou Hydrological experiment station. The results showed that the SMC at different depths in wheat fields was higher than in maize fields, and the SMC of the field showed a trend of increasing and then decreasing with the increase of soil depth. The frequency of soil-atmosphere exchange in the $0-10 \mathrm{~cm}$ soil is significantly lower than the SMC in other soil depths. In general, the SMC in the study area is of moderate variability. The demarcation line between the active and sub-active layers occur at $30 \mathrm{~cm}$. Finally, Ground temperature, groundwater depth, relative humidity, and wheat growth period are the main factors affecting SMC changes in wheat fields; and groundwater depth, relative humidity, and water vapor pressure difference are the main factors affecting SMC changes in maize fields. In addition, this study highlights that rainfall is the main factor influencing the variation of SMC from 0-30 $\mathrm{cm}$ and groundwater depth is the main factor influencing the variation of SMC from $30-100 \mathrm{~cm}$ (rainy season). This is closely related to the fact that the study area belongs to a shallow buried groundwater zone. Further investigations are still needed to investigate how different environmental factors (meteorological factors, soil properties, and vegetation types, etc.) interact to influence SMC variability.

Author Contributions: Conceptualization, J.Z. and G.W.; data curation, Z.W. and Y.H.; formal analysis, M.D., H.L. and N.G.; funding acquisition, Q.Y., C.L., Z.B. and G.W.; investigation, Z.W. and Y.H.; methodology, J.Z., Q.Y., C.L., Z.B., Y.L., J.J. and G.W.; resources, Z.W. and Y.H.; software, M.D., A.E., H.L. and N.G.; Visualization, A.E.; Writing—original draft, M.D.; Writing—review \& editing, J.Z., A.E., Q.Y., C.L., Z.B., Y.L., J.J. and G.W. All authors have read and agreed to the published version of the manuscript.

Funding: This study has been financially supported by the National Key Research and Development Programs of China, China (2016YFA0601501), the National Natural Science Foundation of China, China $(41830863 ; 51879162 ; 52079026 ; 41601025)$, and the Belt and Road Fund on Water and Sustainability of the State Key Laboratory of Hydrology-Water Resources and Hydraulic Engineering, China (2019nkzd02).

Data Availability Statement: The data presented in this study are available on request from the corresponding author or the first author.

Conflicts of Interest: The authors declare no conflict of interest.

\section{References}

1. Brocca, L.; Ciabatta, L.; Massari, C.; Camici, S.; Tarpanelli, A. Soil moisture for hydrological applications: Open questions and new opportunities. Water 2017, 9, 140. [CrossRef]

2. Mccoll, K.A.; Alemohammad, S.H.; Akbar, R.; Konings, A.G.; Yueh, S.; Entekhabi, D. The global distribution and dynamics of surface soil moisture. Nat. Geosci. 2017, 10, 100-104. [CrossRef] 
3. Queiroz, M.G.D.; Silva, T.G.F.D.; Zolnier, S.; Jardim, A.M.D.R.; Souza, S.B.D. Spatial and temporal dynamics of soil moisture for surfaces with a change in land use in the semi-arid region of Brazil. Catena 2020,188, 104457. [CrossRef]

4. Ghajarnia, N.; Kalantari, Z.; Orth, R.E.; Destouni, G. Close co-variation between soil moisture and runoff emerging from multi-catchment data across Europe. Sci. Rep.-UK 2020, 10, 1-11. [CrossRef]

5. Wasko, C.; Nathan, R. Influence of changes in rainfall and soil moisture on trends in flooding. J. Hydrol. 2019, 575, 432-441. [CrossRef]

6. Vereecken, H.; Huisman, J.A.; Bogena, H.; Vanderborght, J.; Vrugt, J.A.; Hopmans, J.W. On the value of soil moisture measurements in vadose zone hydrology: A review. Water Resour. Res. 2008, 44, W00D06. [CrossRef]

7. Chen, H.; Zhang, W.; Wang, K.; Al, E. Soil moisture dynamics under different land uses on karst hillslope in northwest Guangxi, China. Environ. Earth Sci. 2010, 61, 1105-1111. [CrossRef]

8. Gwak, Y.; Kim, S. Factors affecting soil moisture spatial variability for a humid forest hillslope. Hydrol. Process. 2017, 31, 431-445. [CrossRef]

9. Penna, D.; Brocca, L.; Borga, M.; Fontana, G.D. Soil moisture temporal stability at different depths on two alpine hillslopes during wet and dry periods. J. Hydrol. 2013, 477, 55-71. [CrossRef]

10. Chaney, N.W.; Roundy, J.K.; Herrera-Estrada, J.E.; Wood, E.F. High-resolution modeling of the spatial heterogeneity of soil moisture: Applications in network design. Water Resour. Res. 2015, 51, 619-638. [CrossRef]

11. Fang, X.N.; Zhao, W.W.; Wang, L.X.; Feng, Q.; Ding, J.Y.; Liu, Y.X.; Zhao, X. Variations of deep soil moisture under different vegetation types and influencing factors in a watershed of the Loess Plateau, China. Hydrol. Earth Syst. Sci. 2016, 20, 3309-3323. [CrossRef]

12. Oldak, A.; Jackson, T.J.; Pachepsky, Y. Using GIS in passive microwave soil moisture mapping and geostatistical analysis. Int. J. Geogr. Inf. Sci. 2002, 16, 681-698. [CrossRef]

13. Rosenbaum, U.; Bogena, H.R.; Herbst, M.; Huisman, J.A.; Peterson, T.J.; Weuthen, A.; Western, A.W.; Vereecken, H. Seasonal and event dynamics of spatial soil moisture patterns at the small catchment scale. Water Resour. Res. 2012, 48, W10544. [CrossRef]

14. Coenders-Gerrits, A.; Hopp, L.; Savenije, H.; Pfister, L. The effect of spatial throughfall patterns on soil moisture patterns at the hillslope scale. Hydrol. Earth Syst. Sci. 2013, 17, 1749-1763. [CrossRef]

15. Yang, L.; Wei, W.; Chen, L.; Chen, W.; Wang, J. Response of temporal variation of soil moisture to vegetation restoration in semi-arid Loess Plateau, China. Catena 2014, 115, 123-133. [CrossRef]

16. Sur, C.Y.; Jung, Y.; Choi, M. Temporal stability and variability of field scale soil moisture on mountainous hillslopes in Northeast Asia. Geoderma 2013, 207, 234-243. [CrossRef]

17. Cho, E.; Choi, M. Regional scale spatio-temporal variability of soil moisture and its relationship with meteorological factors over the Korean peninsula. J. Hydrol. 2014, 516, 317-329. [CrossRef]

18. Thierfelder, T.K.; Grayson, R.B.; Rosen, D.V.; Western, A.W. Inferring the location of catchment characteristic soil moisture monitoring sites. Covariance structures in the temporal domain. J. Hydrol. 2003, 280, 13-32. [CrossRef]

19. Dong, J.N.; Ochsner, T.E. Soil texture often exerts a stronger influence than precipitation on mesoscale soil moisture patterns. Water Resour. Res. 2018, 54, 2199-2211. [CrossRef]

20. Kim, S.; Kim, H. Stochastic analysis of soil moisture to understand spatial and temporal variations of soil wetness at a steep hillside. J. Hydrol. 2007, 341, 1-11. [CrossRef]

21. Chang, Q.Q.; He, H.L.; Niu, Z.E.; Ren, X.L.; Zhang, L.; Sun, W.X.; Zhu, X.B. Spatio-temporal variation of soil moisture and its influencing factors in Chinese typical forest ecosystems. Acta Ecologica Sinica 2021, 41, 490-502, (In Chinese with English abstract).

22. Mei, X.M.; Zhu, Q.K.; Ma, L.; Zhang, D.; Liu, H.F.; Xue, M.J. The spatial variability of soil water storage and its controlling factors during dry and wet periods on loess hillslopes. Catena 2018, 162, 333-344. [CrossRef]

23. Genuchten, M.T.V.; Wierenga, P.J. Mass Transfer Studies in Sorbing Porous Media I. Analytical Solutions. Soil Sci. Soc. Am. J. 1976, 40, 473-480. [CrossRef]

24. Gregory, A.S.; Bird, N.R.; Whalley, W.R.; Matthews, G.P.; Young, I.M. Deformation and shrinkage effects on the soil water release characteristic. Soil Sci. Soc. Am. J. 2010, 74, 1104-1112. [CrossRef]

25. Brooks, R.H.; Corey, A.T. Properties of Porous Media Affecting Fluid Flow. J. Irrig. Drain. 1964, 92, 61-88. [CrossRef]

26. Sun, M.; Ren, A.; Gao, Z.; Wang, P.; Mo, F.; Xue, L.; Lei, M. Long-term evaluation of tillage methods in fallow season for soil water storage, wheat yield and water use efficiency in semiarid southeast of the Loess Plateau. Field Crop. Res. 2018, $218,24-32$. [CrossRef]

27. Si, M.K.; Cao, J.S.; Yang, H.; Zhu, C.Y. Soil water variation of different vegetation community in Taihang Mountain Area. Chin. J. Eco-Agric. 2020, 28, 1766-1777, (In Chinese with English abstract).

28. Huang, Z.; Liu, Y.; Cui, Z.; Fang, Y.; He, H.; Liu, B.; Wu, G. Soil water storage deficit of alfalfa (Medicago sativa) grasslands along ages in arid area (China). Field Crop. Res. 2018, 221, 1-6. [CrossRef]

29. Gu, F.; Ren, T.S.; Li, B.G.; Li, L.J. Accounting for calcareous concretions in calcic vertisols improves the accuracy of soil hydraulic property estimations. Soil Sci. Soc. Am. J. 2017, 81, 1296-1302. [CrossRef]

30. Savva, Y.; Szlavecz, K.; Carlson, D.; Gupchup, J.; Szalay, A.; Terzis, A. Spatial patterns of soil moisture under forest and grass land cover in a suburban area, in Maryland, USA. Geoderma 2013, 192, 202-210. [CrossRef]

31. Zhang, L.; Zhu, Z.Y.; Zhang, S.W.; Wang, H.M. Analysis of soil moisture variation and its influencing factors in semi-arid steppe watershed. Trans. Chin. Soc. Agric. Eng. 2020, 36, 124-132, (In Chinese with English abstract). 
32. Giraldo, M.A.; Madden, M.; Bosch, D. Land use/land cover and soil type covariation in a heterogeneous landscape for soil moisture studies using point data. GIsci. Remote Sens. 2009, 46, 77-100. [CrossRef]

33. Yang, J.; Chen, H.S.; Nie, Y.P.; Wang, K.L. Dynamic variations in profile soil water on karst hillslopes in Southwest China. Catena 2019, 172, 655-663. [CrossRef]

34. Liu, R.H.; Zhu, Z.X.; Fang, W.S.; Deng, T.H.; Zhao, G.Q. Distribution pattern of winter wheat root system. Chin. J. Ecol. 2008, 27, 2024-2027, (In Chinese with English abstract).

35. Wei, L.R.; Miao, L.J.; Ming, B.Y.; Qing, A.S.; Liang, H.; Lu, J.L.; Le, Z.Y.; Cao, Y.J. Spatial distribution and temporal variation of maize root in the soil under field conditions. Chin. J. Eco-Agric. 2014, 22, 284-291, (In Chinese with English abstract).

36. Zhang, M.; Liu, S.; Liu, Y.; Zhang, H. Soil moisture variation characteristics of different land use types in the moderate slope sandy area of loess hilly region. J. Soil Water Conserv. 2019, 33, 115-120+128, (In Chinese with English abstract).

37. Guderlea, M.; Bachmann, D.; Milcu, A.; Gockele, A. Dynamic niche partitioning in root water uptake facilitates efficient water use in more diverse grassland plant communities. Funct. Ecol. 2018, 32, 214-227. [CrossRef]

38. Zhen, Z.; Yi, L.Y.; Jun, G.J.; Jing, W.; Hao, D.G.; Hui, G.Z.; Cheng, P.H. Effect of tillage depth on soil physical properties and yield of winter wheat-summer maize. Trans. Chin. Soc. Agric. Eng. 2017, 33, 115-123, (In Chinese with English abstract).

39. Svetlitchnyi, A.A.; Plotnitskiy, S.V.; Stepovaya, O.Y. Spatial distribution of soil moisture content within catchments and its modelling on the basis of topographic data. J. Hydrol. 2003, 277, 50-60. [CrossRef]

40. Broedel, E.; Tomasella, J.; Candido, L.A.; Von Randow, C. Deep soil water dynamics in an undisturbed primary forest in central Amazonia: Differences between normal years and the 2005 drought. Hydrol. Process. 2017, 31, 1749-1759. [CrossRef]

41. Chen, X.; Hu, Q. Groundwater influences on soil moisture and surface evaporation. J. Hydrol. 2004, 297, 285-300. [CrossRef]

42. Han, X.S.; Wang, Y.H.; Yu, P.T.; Xiong, W.; Li, Z.H.; Cai, J.J.; Xu, H. Temporal and spatial variation and influencing factors of soil moisture in larix principis-rupprechtii plantation in Semiarid Liupan Mountains, Northwest China. J. Soil Water Conserv. 2019, 33, 111-117, (In Chinese with English abstract).

43. Li, X.Y.; Liu, L.; Li, H.; Wang, S.P.; Heng, J. Spatiotemporal soil moisture variations associated with hydro-meteorological factors over the Yarlung Zangbo River basin in Southeast Tibetan Plateau. Int. J. Climatol. 2019, 40, 188-206. [CrossRef]

44. Wang, T.J.; Franz, T.E. Field observations of regional controls of soil hydraulic properties on soil moisture spatial variability in different climate zones. Vadose Zone J. 2015, 14, 1-8. [CrossRef]

45. Biswas, A.; Si, B.C. Revealing the Controls of Soil Water Storage at Different Scales in a Hummocky Landscape. Soil Sci. Soc. Am. J. 2011, 75, 1295-1306. [CrossRef]

46. Joshi, C.; Mohanty, B.P.; Jacobs, J.M.; Ines, A.V.M. Spatiotemporal analyses of soil moisture from point to footprint scale in two different hydroclimatic regions. Water Resour. Res. 2011, 47, 1-20. [CrossRef] 